\title{
THE EFFECT OF INTRAVENOUS INFUSIONS OF PHYSIOLOGIC SALINE SOLUTION ON THE PULMONARY ARTERIAL AND PULMONARY CAPILLARY PRESSURE IN MAN ${ }^{1}$
}

\author{
By JOSEPH T. DOYLE, 2 JOSEPH S. WILSON, ${ }^{3}$ E. HARVEY ESTES, ${ }^{*}$ AND \\ JAMES V. WARREN
}

(From the Departments of Medicine and Physiology, Emory University School of Medicine, and the Medical Service, Grady Memorial Hospital, Atlanta, Ga.)

(Submitted for publication November 11, 1950; accepted, January 8, 1951)

In view of the possible role of an increased blood volume in the development of certain features of congestive heart failure, we have undertaken an investigation of experimentally induced changes in plasma volume. The present report deals with the effect of rapid intravenous infusions of physiologic saline solution on the pulmonary arterial and capillary pressure of normal human subjects.

\section{METHODS}

Twelve adult men ranging in age from 17 to 64 years and convalescent from noncardiac ailments were studied. The subjects were in the post-absorptive state and in the recumbent position. The pulmonary artery was catheterized by the usual technique (1). An indwelling needle was inserted into a peripheral artery. Expired air was collected for three minutes in a Douglas bag. The oxygen content of the blood samples was determined by the method of Van Slyke and Neill (2) and of the air samples by the method of Haldane (3). The cardiac output was calculated utilizing the Fick principle.

The so-called pulmonary blood volume was determined by the dye dilution method of Stewart and Hamilton $(4,5)$ as modified by Ebert (6). An accurately measured amount of T-1824 was injected into the cardiac catheter and the arterial blood sampled for two-second periods for 22 seconds after the injection. A ten-minute arterial blood specimen was obtained for estimation of the initial general blood volume. Subsequent blood volumes were calculated from the hematocrit reading, assuming the red blood cell mass to remain constant. The mean pulmonary circulation time and the cardiac output were calculated from the dye time-concentration curve and in turn the pulmonary blood volume was derived.

The instantaneous and mean pulmonary arterial pressure curves were measured from a zero level $5 \mathrm{~cm}$. below the sternal angle by a Sanborn electromanometer and registered with a simultaneous electrocardiographic lead

\footnotetext{
1 This study was supported in part by a grant from the American Heart Association.

2 Whitehead Foundation Research Fellow, 1949-50.

${ }^{3}$ Whitehead Foundation Research Fellow, 1950-51.

${ }^{4}$ Alfred Stengel Research Fellow of the American College of Physicians.
}

on a Sanborn Polyviso recorder. The so-called pulmonary capillary pressure was measured by the method of Dexter (7). The heart rate was determined from the electrocardiogram.

After completion of these control observations, physiologic saline solution was injected into a peripheral vein at rates of from $77-146 \mathrm{cc}$. per minute in amounts of 950-1,000 cc. During this time the pulmonary arterial pressure was measured continuously or at frequent intervals. Toward the end of the infusion period the cardiac output and the pulmonary blood volume were again determined. The infusion was then discontinued and in most instances the cardiac output was determined a third time at varying subsequent intervals.

Measurements of the vital capacity were made on eight subjects at various times during the experimental period.

\section{RESULTS}

In each of the 12 cases there was a rise in the pulmonary arterial pressure evident within one or two minutes and continuing to increase throughout the infusion period (Table I). The mean resting pulmonary arterial pressure of $7-15 \mathrm{~mm}$. $\mathrm{Hg}$ (average $12 \mathrm{~mm} . \mathrm{Hg}$ ) rose to levels of $16-25 \mathrm{~mm}$. $\mathrm{Hg}$ (average $20 \mathrm{~mm} . \mathrm{Hg}$ ), representing increases of from 43-150 per cent. Both the systolic and diastolic pressures participated in the rise although the pulse pressure often widened moderately. Within 15 to 60 minutes after the infusion the mean pulmonary arterial pressure had returned to or toward normal.

In four cases tabulated and in four other cases not tabulated here, the rapid infusion of saline solution caused an increase in the pulmonary capillary pressure proportional to that observed in the pulmonary artery. Percentagewise the increase was greater because of the low initial level of the capillary pressure.

Hemodilution at the end of the infusion was indicated by a fall in the hematocrit reading averaging 13 per cent and by an average increase in the general blood volume of 14 per cent. This repre- 


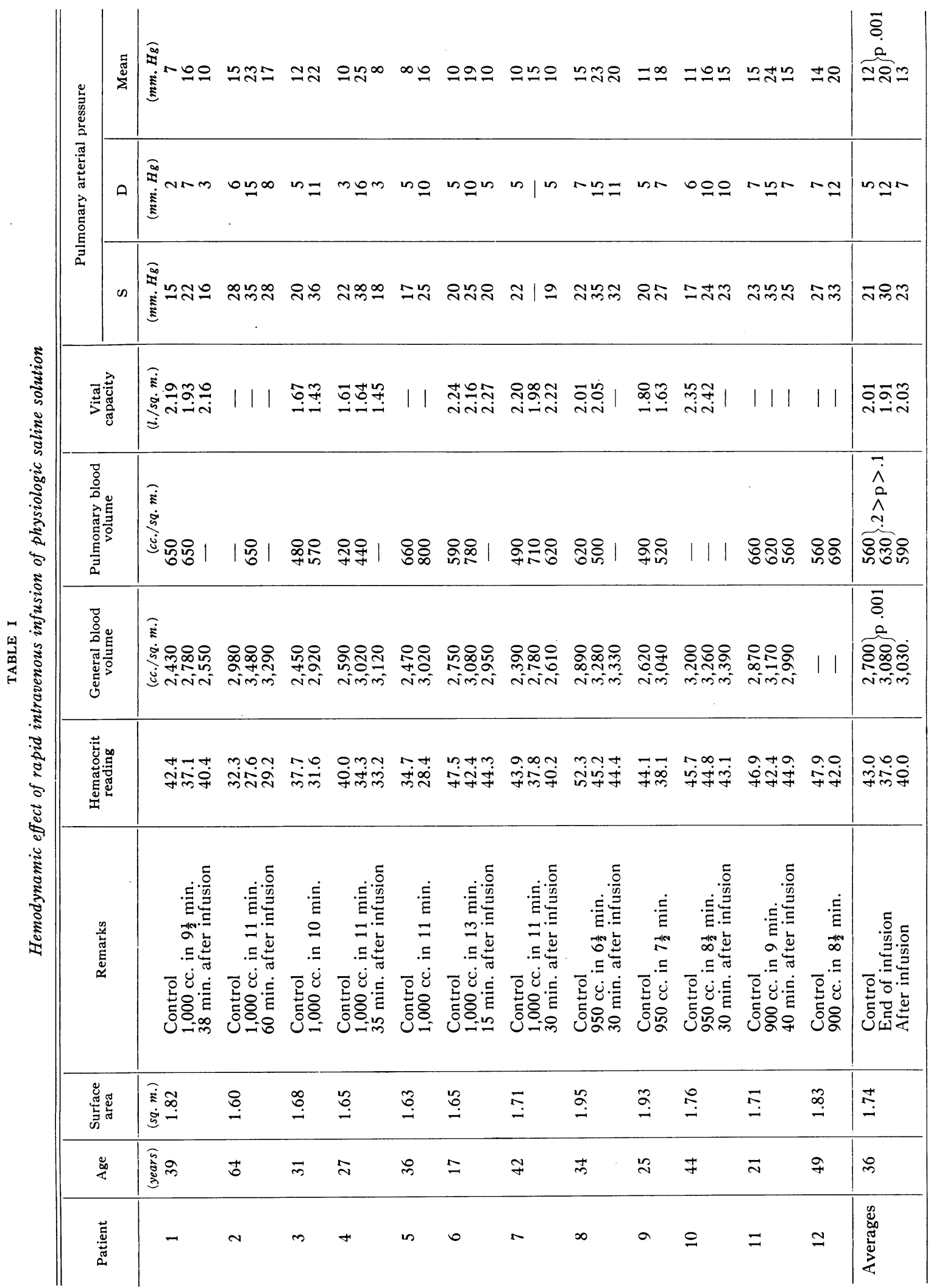




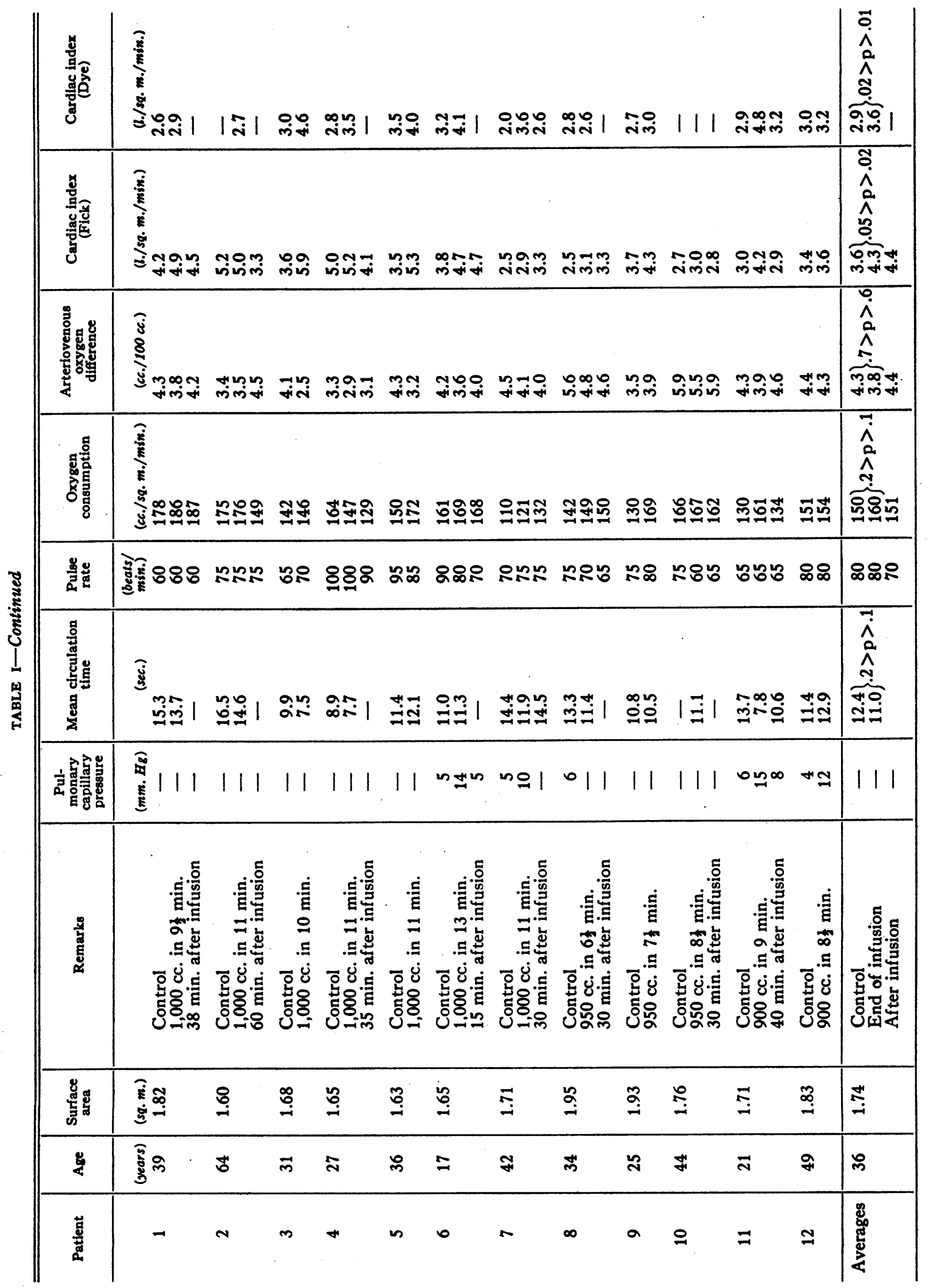


sented an increase in plasma volume of approximately $385 \mathrm{cc}$. per square meter in an average subject.

In 10 cases the pulmonary blood volume showed an average post-infusion increase of 12 per cent with variations from -6 to +45 per cent of the control value. Both before and after the infusion the pulmonary blood volume amounted to about 20 per cent of the general blood volume. Individually, measured increases in the pulmonary and the general blood volumes were not always proportional. Five of eight subjects showed a decrease in the vital capacity at the end of the infusion.

The response of the cardiac output to the infusion was variable. The minute oxygen consumption rose slightly after the infusion. The arteriovenous oxygen difference and the central circulation time in general were somewhat reduced by the infusion. In six cases there was a significant increase in the cardiac output after the infusion while six remained within the limits of experimental error. In six out of eight cases, the third cardiac output was the same as or below the control level.

The pulse rate remained remarkably constant during the control and rapid infusion periods. In four patients repeated direct arterial pressure measurements failed to demonstrate a significant change following the saline infusion. Distention of the peripheral veins was regularly observed. Flushing of the skin was not seen. None of the subjects complained of dyspnea.

\section{DISCUSSION}

In every instance the pulmonary arterial and pulmonary capillary pressures were promptly and strikingly increased by the infusion of physiologic saline solution. A similar response has been observed following the transfusion of whole blood and the infusion of isotonic glucose and dextran solutions (8). Conversely, observations in this laboratory have demonstrated that a reduction of the effective circulating blood volume, caused by the application of venous-occluding tourniquets about the thighs, produces a lowering of the pulmonary arterial pressure (9). These data suggest that an abrupt, if not large, alteration in blood volume is the common denominator producing the observed pulmonary pressure changes.

On theoretical grounds the rise in pulmonary

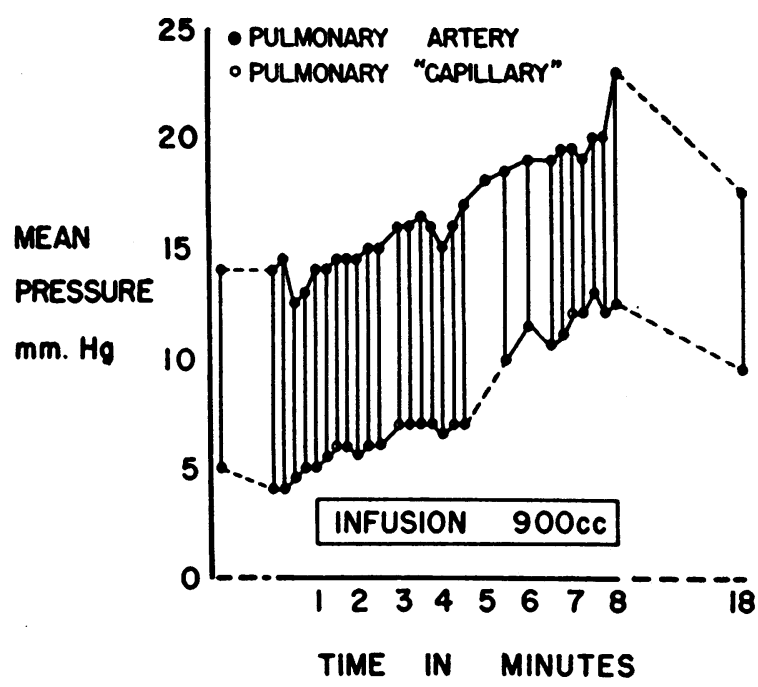

Fig. 1. Simultaneous Measurement of Pulmonary Arterial and Capillary Pressures during a Rapid SaLINE INFUSION

There was no significant change in cardiac output.

arterial pressure following an infusion might be the result of an increased cardiac output and therefore an increased pulmonary blood flow; of increased pulmonary resistance due to vasoconstriction within the lungs; or of an increased volume of blood contained within the pulmonary vascular bed.

The fact that the rise in pulmonary arterial pressure was the result of a rapid infusion suggested that the pressure elevation might be the result of increased flow through the pulmonary circuit. Although an increased cardiac output, and therefore an increased pulmonary flow, did occur in six instances, in the other six there was only an insignificant change in the cardiac output, yet the hypertension also resulted. In addition, there was no correlation between the magnitude of the increase in the pulmonary arterial pressure and the changes in cardiac output which did occur. This finding is not entirely surprising because previous observations on normal subjects during light exercise (10) and on patients during temporary occlusion of arteriovenous fistulas (11) have demonstrated that a considerable change in the cardiac output may occur without any alteration in the pulmonary arterial pressure.

As in the case of the pulmonary arterial pressure, there was an increase in the so-called pulmonary capillary pressure in all the patients observed. Although continuous and simultaneous 
pressure readings of this function and of the pulmonary arterial pressure were not usually technically possible, intermittent readings gave evidence that there was little or no change in the pressure relationships between the two areas. In one experiment two catheters were introduced, one measuring the pulmonary arterial and the other pulmonary capillary pressure. It was demonstrated that a saline infusion raised both pressures, the gradient between the two remaining constant (Figure 1). The evidence of an elevated pulmonary capillary pressure indicates that quite probably the pulmonary venous pressure is also increased. Indeed, it may be that the pressure measured by this technique actually represents the left atrial pressure rather than the pulmonary capillary pressure (12), for the contours often show typical a-c-v waves. Further support to the concept that intravenous infusions raise the venous as well as the arterial pressure in the pulmonary circuit has been obtained from animal experiments in which both pressures were simultaneously measured with catheters in the pulmonary artery and the pulmonary vein (13). With large infusions it was found that both pressures rise, and that the venous pressure eventually approaches the elevated pulmonary arterial pressure. These data, therefore, indicate that the intravenous infusions in our patients produced a rise in the pulmonary arterial, capillary and venous pressures without gross alteration in the pressure relationships between these three components of the pulmonary circuit.

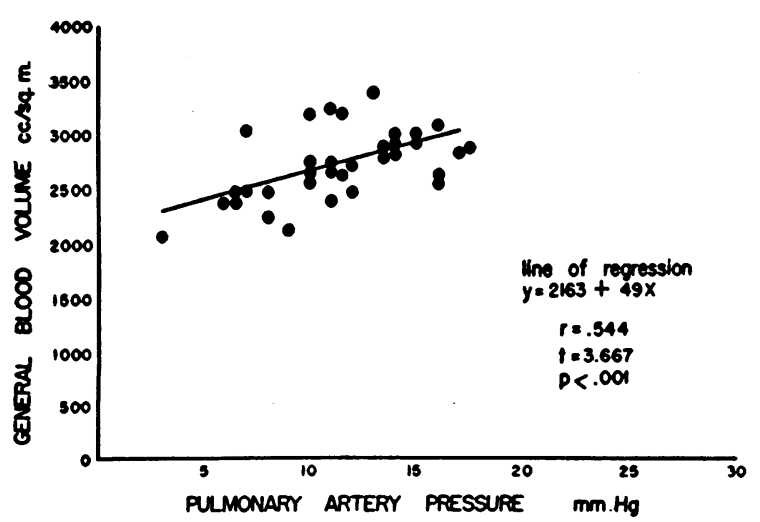

Fic. 2. The Relationship between the General Blood Volume and the Pulmonary Arterial Pressure in Subjects with Normal Cardiopulmonary Function under Relatively Basal Conditions
TABLE II

Observations on patients with normal cardiopulmonary functions under relatively basal conditions

\begin{tabular}{|c|c|c|c|c|c|c|}
\hline Patient & Age & $\begin{array}{c}\text { Surface } \\
\text { area }\end{array}$ & $\begin{array}{c}\text { Hemato- } \\
\text { crit } \\
\text { reading }\end{array}$ & $\begin{array}{c}\text { Blood } \\
\text { volume }\end{array}$ & $\begin{array}{c}\text { Pul- } \\
\text { monary } \\
\text { arterial } \\
\text { pressure }\end{array}$ & $\begin{array}{c}\text { Cardiac } \\
\text { index } \\
\text { (Fick) }\end{array}$ \\
\hline $\begin{array}{l}1 \\
2 \\
3 \\
4 \\
5 \\
6^{*} \\
7 \\
8 \\
9 \\
10 \\
11 \\
12 \\
13^{*} \\
14^{*} \\
15^{*} \\
16 \\
17^{*} \\
18^{*} \\
19 \\
20^{*} \\
21 \\
22 \\
23 \\
24^{*} \\
25 \\
26 \\
27 \\
28 \\
29^{*} \\
30 \\
31^{*} \\
32^{*} \\
33 \\
34\end{array}$ & $\begin{array}{l}\text { (years) } \\
39 \\
33 \\
59 \\
43 \\
35 \\
17 \\
53 \\
24 \\
20 \\
18 \\
24 \\
56 \\
25 \\
34 \\
42 \\
42 \\
64 \\
31 \\
21 \\
27 \\
39 \\
63 \\
49 \\
39 \\
59 \\
31 \\
34 \\
44 \\
44 \\
34 \\
21 \\
36 \\
47 \\
28\end{array}$ & $\begin{array}{l}\text { (sq. m.) } \\
1.55 \\
1.59 \\
1.62 \\
1.48 \\
1.76 \\
1.65 \\
1.94 \\
1.66 \\
2.04 \\
1.82 \\
1.96 \\
1.68 \\
1.93 \\
1.95 \\
1.71 \\
1.96 \\
1.60 \\
1.68 \\
1.88 \\
1.65 \\
1.85 \\
1.61 \\
1.91 \\
1.82 \\
1.77 \\
1.30 \\
1.87 \\
1.40 \\
1.76 \\
1.51 \\
1.71 \\
1.63 \\
1.82 \\
1.66\end{array}$ & $\begin{array}{l}38.4 \\
41.6 \\
28.1 \\
34.0 \\
49.0 \\
47.5 \\
44.0 \\
41.7 \\
38.1 \\
48.0 \\
31.6 \\
39.0 \\
44.1 \\
52.3 \\
43.9 \\
44.9 \\
32.3 \\
37.7 \\
43.8 \\
40.0 \\
36.5 \\
47.5 \\
36.8 \\
42.4 \\
43.9 \\
27.0 \\
32.9 \\
34.0 \\
45.7 \\
38.5 \\
46.9 \\
34.7 \\
39.2 \\
48.5\end{array}$ & $\begin{array}{l}\text { (cc./ } \\
\text { se. } m .) \\
2,710 \\
3,080 \\
2,360 \\
2,700 \\
3,030 \\
2,750 \\
3,230 \\
2,980 \\
2,850 \\
2,630 \\
2,400 \\
2,120 \\
2,620 \\
2,830 \\
2,390 \\
2,860 \\
2,980 \\
2,450 \\
2,970 \\
2,590 \\
2,050 \\
2,940 \\
2,610 \\
2,430 \\
3,380 \\
2,710 \\
2,250 \\
2,560 \\
3,200 \\
2,470 \\
2,870 \\
2,470 \\
3,180 \\
2,820\end{array}$ & $\begin{array}{r}(m m . H g) \\
11.0 \\
16.0 \\
6.0 \\
12.0 \\
7.0 \\
10.0 \\
11.0 \\
14.0 \\
14.0 \\
10.0 \\
6.5 \\
9.0 \\
11.5 \\
17.0 \\
11.0 \\
17.5 \\
15.0 \\
12.0 \\
14.0 \\
10.0 \\
3.0 \\
15.0 \\
16.0 \\
6.5 \\
13.0 \\
11.0 \\
8.0 \\
16.0 \\
11.5 \\
8.0 \\
13.5 \\
7.0 \\
10.0 \\
13.5\end{array}$ & 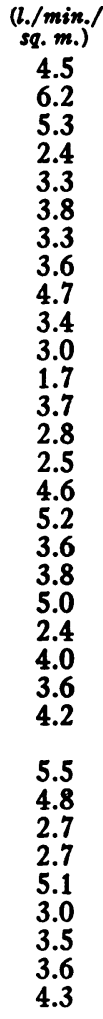 \\
\hline $\begin{array}{l}\text { ean } \\
\text { D. }\end{array}$ & 37.5 & 1.73 & 40.4 & $\begin{array}{l}2,720 \\
\pm 316\end{array}$ & $\begin{array}{c}11.4 \\
\pm 3.49\end{array}$ & $\begin{array}{c}3.8 \\
\pm 1.03\end{array}$ \\
\hline
\end{tabular}

* Denotes patients receiving saline infusions and included in Table $\mathrm{I}$.

The maintenance of essentially normal pressure gradients throughout the pulmonary circuit in subjects receiving rapid infusions is considered as evidence against the occurrence of pulmonary arteriolar constriction as the cause of the pressure changes in these subjects. Had arteriolar constriction been the cause of the increased pulmonary arterial pressure, little or no increase in the pulmonary capillary pressure would have been observed. Further evidence against vasoconstriction was obtained by examination of the contour of the pulmonary arterial pressure tracings which revealed no indication of decreased "run-off" during diastole.

If increased flow and increased resistance due 
to arteriolar constriction may be eliminated as the fundamental mechanisms producing the pulmonary hypertension, it becomes necessary to explore the possibility of an increased volume of blood in the lungs.

First, the possible relationship of the pulmonary arterial pressure to the volume of blood in the pulmonary circuit under relatively basal conditions was investigated. A study of the so-called "pulmonary blood volume" failed to show good correlation with the pulmonary pressures. On the other hand, the relationship of the pulmonary arterial pressure to the general blood volume revealed a striking correlation. This is demonstrated in Figure 2, where in addition to the observations made in this study, there are included for further statistical validation 22 points derived from studies by the same methods on additional patients with normal cardiopulmonary function made under relatively basal conditions (Table II). A linear relationship of good statistical significance is demonstrated. If the results obtained on the effect of saline infusions are plotted in a similar way, they will be seen to follow clasely the line of regression derived from the observations on normal subjects under basal conditions (Figure 3 ). Although the line of regression is represented as straight, it is very possible that in actuality it is curved and follows more nearly the pressure-volume relationship shown by elastic structures or, more particularly, by isolated segments of veins $(14,15)$. Apparently, however, under the conditions of our studies, the relationship between the blood volume and the pulmonary arterial pressure is nearly linear. Infusion of one liter of saline solution in our human subjects, however, gave no evidence of the disproportionately large rise in pulmonary pressures such as reported in the open-chested dog by Opdyke and associates (16).

The studies reported here indicate that the ratio between the quantities of blood contained in the pulmonary and the systemic circuits is not altered by a rapid expansion of the general blood volume. Yet, because of the pressure-volume relationship present in the pulmonary venous-left atrial segment, this small increase in blood content produced a considerable increase in pulmonary pressures. Similar evidence in the opposite direction is available from the study of blood loss in normal human subjects (8). If there were disproportionate addition to or loss from the pulmonary circulation, or if pulmonary vasomotor activity were stimulated, the relationship demonstrated in Figure 2 would not hold and the plotted

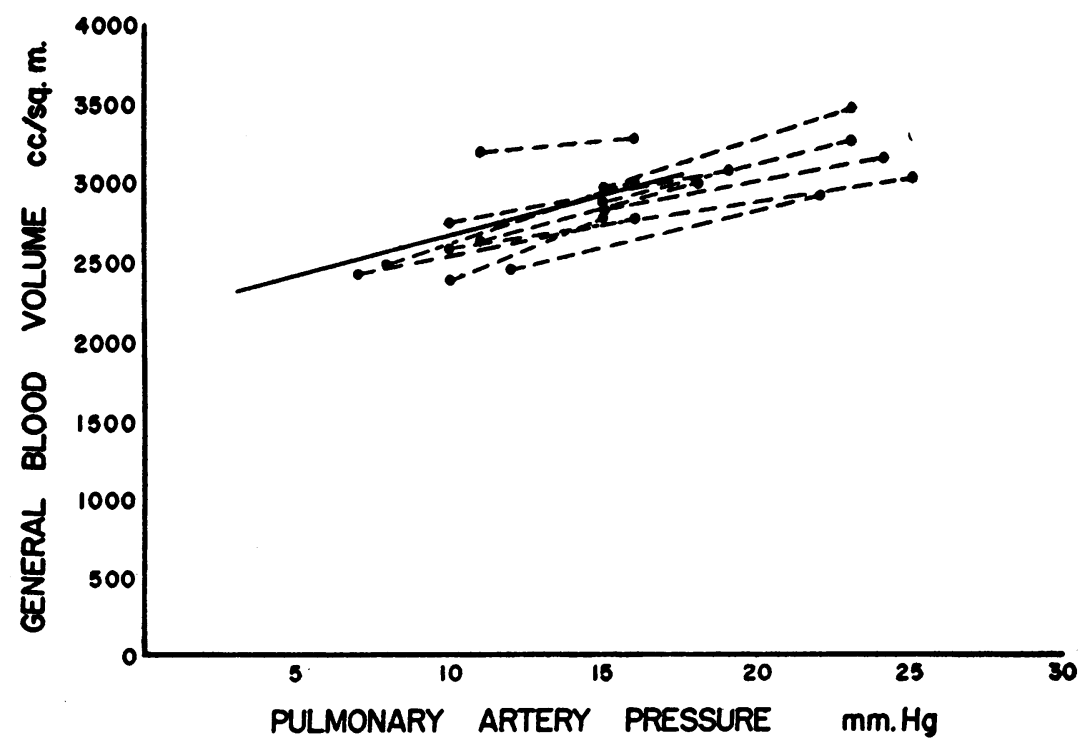

Fig. 3. The Relationship of the General Blood Volume and the PULmonary Arterial Pressure in Normal Subjects Receiving Saline INFUSIOŃS

In each case the pulmonary arterial pressure rises. The line of regression is that obtained from Figure 2. 
results would not fall on the line of regression. During hypoxia in normal subjects and in certain pathologic situations such a disproportion does occur (8). These pressure relationships are evidence against, but do not eliminate the unlikely possibility that our infusions produced acute cardiac failure.

The reason for the absence of a good correlation between the observed pulmonary arterial pressure and the measured pulmonary blood volume in our studies is not apparent. The mean values show the expected directional trend but the individual values appear to be somewhat erratic. It is felt probable that changes in the pulmonary volume of the order of 50-100 cc., as induced in many of these experiments, are not sufficiently beyond the range of error in the measurement itself (8).

Insofar as one can measure the filling pressure from observations made at one point, it is interesting to note that despite the evidence of an increase in the pulmonary venous, and therefore the left heart filling pressure, there was not a consistent increase in the left ventricular output. These data are compatible with the concept that alterations in the filling pressure are not a major factor in producing changes in the cardiac output in the human being (17).

It has been demonstrated previously that intravenous infusions similar to those utilized here produce an increase in the right ventricular, right atrial, central venous and peripheral venous pressures $(8,18)$. Although simultaneous readings of these pressures and those in the pulmonary circuit are not available, the evidence indicates that the rise produced is essentially the same throughout the venous and pulmonary circuit. The normal pressure gradients appear to be maintained thereby from peripheral vein to left atrium, but at a higher level following the infusion.

In the present study the pulse rate remained remarkably constant from the control through the infusion period. This failure to observe the Bainbridge reflex in the normal human has been observed previously in this laboratory (18).

It is difficult to assess the relationship of the pulmonary hypertension produced in these studies to that occurring in patients with cardiac disease. These experiments, as well as other recently reported observations $(19,20)$, demonstrate the oc- currence of elevations in the pulmonary capillary pressure of such magnitude as adequately to account for the production of pulmonary edema without implication of changes in capillary permeability. Further studies are under way on the effect of manipulations similar to those described here on the pulmonary hemodynamics of patients with cardiac and pulmonary disease.

\section{SUMMARY}

In the normal human subject the pulmonary arterial and the pulmonary capillary pressure can be significantly increased by the rapid intravenous infusion of physiologic saline solution. The pulmonary and the general blood volumes increase proportionately after this maneuver. The cardiac output after a rapid infusion may or may not increase.

There is a linear correlation between the resting pulmonary arterial pressure and the general blood volume in normal subjects but this relationship is not apparent in the case of the pulmonary blood volume as measured by the dye technique. The same relationship continues after an increase in the blood volume with saline solution. It is suggested that the changes induced by a rapid infusion can be explained most adequately on the basis of an abrupt, but not disproportionate, increase in the amount of blood contained in the relatively indistensible pulmonary circuit.

\section{ACKNOWLEDGMENT}

This work was carried out with the technical assistance of Misses Eloise Cavin, Mary Upshaw, Voncile Williams, Elizabeth Kelley, Mrs. Fransetta Latimer, and Mrs. Louise Thompson.

\section{REFERENCES}

1. Warren, J. V., Determination of cardiac output in man by right heart catheterization, in Methods in Medical Research, edited by Potter, V. R. Yearbook Publishers, Chicago, 1948, Vol. I.

2. Van Slyke, D. D., and Neill, J. M., The determination of gases in blood and other solutions by vacuum extraction and manometric measurement. $J$. Biol. Chem., 1924, 61, 523.

3. Peters, J. P., and Van Slyke, D. D., Quantitative Clinical Chemistry. Vol. II, Methods. Williams \& Wilkins Co., Baltimore, 1932.

4. Stewart, G. N., The output of the heart in dogs. Am. J. Physiol., 1921, 57, 27. 
5. Hamilton, W. F., Moore, J. W., Kinsman, J. M., and Spurling, R. G., Studies on the circulation. IV. Further analysis of the injection method, and of changes in hemodynamics under physiological and pathological conditions. Am. J. Physiol., 1932, 99, 534.

6. Ebert, R. V., Borden, C. W., Wells, H. S., and Wilson, R. H., Studies of the pulmonary circulation. I. The circulation time from the pulmonary artery to the femoral artery and the quantity of blood in the lungs in normal individuals. J. Clin. Invest., 1949, 28, 1134.

7. Hellems, H. K., Haynes, F. W., and Dexter, L., Pulmonary "capillary" pressure in man. J. Appl. Physiol., 1949, 2, 24.

8. Doyle, J. T., Wilson, J. S., Estes, E. H., Jr., and Warren, J. V., Unpublished observations.

9. Fitzhugh, F. W., McWhorter, R. L., Jr., Estes, E. H., Jr., Merrill, A. J., and Warren, J. V., The effect of pooling blood in the extremities on renal function and hemodynamics. In preparation.

10. Hickam, J. B., and Cargill, W. H., Effect of exercise on cardiac output and pulmonary arterial pressure in normal persons and in patients with cardiovascular disease and pulmonary emphysema. $\mathrm{J}$. Clin. Invest., 1948, 27, 10.

11. Warren, J. V., Cooper, F. W., Jr., and Nickerson, J. L., Cardiac output and intravascular pressures in patients with arteriovenous fistulas. In preparation.

12. Lagerlöf, H., Werko, L., Bucht, H., and Holmgren, A., Studies on the circulation of blood in man. VI. The pulmonary capillary venous pressure pulse in man. Scandinav. J. Clin. \& Lab. Invest., 1949, $1,147$.

13. Cannon, J. L., and Warren, J. V., Effect of saline in- fusions and epinephrine on the pulmonary hemodynamics of the dog. In preparation.

14. Ryder, H. W., Molle, W. E., and Ferris, E. B., Jr., The influence of the collapsibility of veins on venous pressure including a new procedure for measuring tissue pressure. J. Clin. Invest., 1944, 23, 333.

15. Alexander, R. S., In vivo observations on the distensibility of the femoral venous system. Proc. Soc. Exper. Biol. \& Med., 1948, 67, 410.

16. Opdyke, D. F., Duomarco, J., Dillon, W. H., Schreiber, H., Little, R. C., and Seely, R. C., Study of simultaneous right and left atrial pressure pulses under normal and experimentally altered conditions. Am. J. Physiol., 1948, 154, 258.

17. Stead, E. A., Jr., and Warren, J. V., Cardiac output in man; analysis of mechanisms varying cardiac output based on recent clinical studies. Arch. Int. Med., 1947, 80, 237.

18. Warren, J. V., Brannon, E. S., Weens, H. S., and Stead, E. A., Jr., Effect of increasing the blood volume and right atrial pressure on the circulation of normal subjects by intravenous infusions. Am. J. Med., 1948, 4, 193.

19. Haddy, F. J., Campbell, G. S., and Visscher, M. B., Pulmonary vascular pressures in relation to edema production by airway resistance and plethora in dogs. Am. J. Physiol., 1950, 161, 336.

20. Dexter, L., Dow, J. W., Haynes, F. W., Whittenberger, J. L., Ferris, B. G., Goodale, W. T., and Hellems, H. K., Studies of the pulmonary circulation in man at rest. Normal variations and the interrelations between increased pulmonary blood flow, elevated pulmonary arterial pressure, and pulmonary "capillary" pressures. J. Clin. Invest., 1950, 29, 602.

\title{
SPECIAL NOTICE TO SUBSCRIBERS
}

\author{
Post Offices will no longer forward the Journal \\ when you move. \\ Please notify Journal of Clinical Investigation, \\ Business Office, c/o Cincinnati General Hospital, \\ Cincinnati 29, Ohio, at once when you have a change \\ of address and do not omit the zone number if there \\ is one.
}

